\title{
大溪水库和沙河水库主要鱼类营养结构的时空变化
}

\author{
王 媛, 凡迎春, 徐东坡* \\ 农业农村部长江下游渔业资源环境科学观测实验站,中国水产科学研究院淡水渔业研究中心, 无锡 214081
}

\begin{abstract}
摘要: 为了解大溪水库和沙河水库主要鱼类食物网营养结构的时空变化特征,依据 2017 年夏、秋季和 2018 年春季在大溪水库 和沙河水库的调查结果, 利用稳定同位素方法对这两个水域内鱼类的营养关系进行研究,得到以下主要结论: 大溪水库共出现 鱼类 28 种, 沙河水库 29 种, 鱼类群落结构组成结构相似, 呈现出以湖泊定居性鱼类和鲤科鱼类为主的特征。配对双样本时空 差异分析显示, 相同季度内两个水库鱼类的 $\delta^{13} \mathrm{C}$ 值差异显著, 说明两个水库的初级食物源存在明显不同; 相同区域内, 大溪水 库季度差异不明显,而沙河水库差异显著, 说明大溪水库的初级食物源组成变动较沙河水库的更小。 $\delta^{15} \mathrm{~N}$ 值时空变化规律不明 显, 这可能与水库周围农业活动和人类活动的不确定性有关。鱼类群落指标值分析结果显示, 沙河水库的 CR、NR、TA、SEAc、 CD、MNND 和 SDNND 指标值均高于大溪水库, 且春季高于其他季度,这表明沙河水库春季食物网较其他季节、较大溪水库更为 复杂, 食物源更加丰富, 食物链更长, 营养层次更多, 核心生态位宽幅更低, 营养级多样性的总程度更高, 营养生态位均匀度较 低, 大溪水库食物网的圥余程度较高, 说明相较于沙河水库, 大溪水库生态系统稳定性更高, 抗干扰能力更强, 这可能与沙河水 库周边广泛的茶园、旅游区和和居民区密集分布有关。基于各种量化群落指标对大溪水库和沙河水库的食物网结构进行时空 差异分析, 能够为大溪水库和沙河水库水生生态系统的管理与修复提供理论支撑。
\end{abstract}

关键词: 大溪水库;沙河水库;稳定同位素; 营养结构

\section{Temporal and spatial variations in the trophic structure of key species in Daxi and Shahe Reservoir}

WANG Yuan, FAN Yingchun, XU Dongpo*

Scientific Observing and Experimental Station of Fishery Resources and Environment in the Lower Reaches of the Changjiang River, Ministry of Agriculture and Rural Affairs. Freshwater Fisheries Research Center, Chinese Academy of Fishery Sciences, Wuxi 214081, China

\begin{abstract}
Tianmu Lake is the important water resource in the Jiangsu Province, which is composed by Daxi and Shahe Reservoirs with abundant fishery resource. According to the spatio-temporal variation characteristics of main fishes' food web in Daxi and Shahe Reservoirs, the stable isotope ratio data of species were collected from two reservoirs from July 2017 to April 2018, and the nutrient relationship was analyzed for key species at first time. The results showed that 32 fish species were captured from the surveys, of which 28 fish species were sampled from Daxi Reservoir, while 29 fish species were sampled from Shahe Reservoir. The fish structure communities in two reservoirs were similar, dominated by the sedentary fishes and Cyprinidae. The spatio-temporal differences of $\delta^{13} \mathrm{C}$ value and $\delta^{15} \mathrm{~N}$ value were analyzed by the paired samples $\mathrm{t}$ test method. The results indicated that there were significant differences of $\delta^{13} \mathrm{C}$ value between the two reservoirs during the same season. There were no significant differences between each season in Daxi Reservoir but opposite in Shahe Reservoir. It means that two reservoirs had various composition of food sources, and that composition of basal resources of fishes in Daxi Reservoir may be more stable than that in Shahe Reservoir. In addition, there were no obvious variations in spatio-temporal
\end{abstract}

基金项目: 江苏省水生生物资源重大专项暨首次水生野生动物资源普查项目(ZYHB16); 中国水产科学研究院科技创新团队专项(2020TD61)

收稿日期: 2020- 05-26; 网络出版日期: 2021-02-24

* 通讯作者 Corresponding author.E-mail: xudp@ ffrc.cn 
of $\delta^{15} \mathrm{~N}$ value, which may be related to the pollution of agricultural and human activities around the reservoir. The index calculation results showed that range of $\delta^{13} \mathrm{C}(\mathrm{CR})$ and range of $\delta^{15} \mathrm{~N}(\mathrm{NR})$ in Shahe Reservoir were higher than those in Daxi Reservoir, indicating that the food sources were more abundant and the food chains were longer in Shahe Reservoir. Also, the area of convex hull(TA) and standard ellipse area corrected for small sample size ( SEAc) value were higher than Daxi Reservoir, meaning that the trophic levels were more complicated and the core niche space was narrower. Moreover, the mean distance to centroid ( CD), mean nearest-neighbor distance (MNND) and standard deviation of nearest-neighbor distance(SDNND) values were also higher in Shahe Reservoir, showing that the overall degree of trophic diversity was higher but lower evenness nutrient niches in it, while higher redundancy in Daxi Reservoir. In addition, seasonal difference analysis results showed that the six index values were higher in spring than other seasons, meaning that the food web structures in spring were more complex. Comparing with Daxi Reservoir, the investigation showed that Shahe Reservoir had lower stability and less anti-interference ability, which may be correlated with the extensive distribution of tea gardens, tourist and residential area around it. Therefore, based on the quantitative index analysis results above, the study could provide adequate theoretical support for the management and restoration of aquatic ecosystem of Daxi Reservoir and Shahe Reservoir.

Key Words : Daxi Reservoir; Shahe Reservoir; stable isotope; nutrition structure

水生食物网是指水生生态系统中形成的多种生物及取食关系的集合 ${ }^{[1]}$, 水生生物通过营养关系形成相 互依存和相互制约的有机体, 从而实现食物网与外部生境之间的物质循环及能量流动 ${ }^{[2-3]}$ 。传统意义上, 关 于生物群落结构特征的定量分析常采用基本指数如物种组成、丰度、多样性指数等来体现 ${ }^{[4]}$, 但是生物群落 结构在不同的时空下存在较大差异, 而这并不能反映群落稳定性的变化规律 ${ }^{[5-6]}$ 。研究表明, 同位素分馏效 应能够引起不同生物及其组织的稳定同位素比值不同,其值的大小又能够体现多维生态空间信息 ${ }^{[7-8]}$ 。一般 情况下,将生物组织中碳、氮稳定同位素所形成的 “ $\delta$-空间” 称为同位素生态位 ${ }^{[9]}$, 它能够反映物种在不同时 空内所处营养位置的变化特征。layman 等根据形态生态学研究中的物种形态特征二维表示法,提出了关于 生物营养结构的 6 个同位素量化指标 ${ }^{[10]}$, 这些指标不仅可以量化食物网的营养多样性程度和冗余程度, 还能 用于描述物种水平的生态位宽度和重叠度,评估生物及非生物环境因素对食物网特征变化的影响等 ${ }^{[11-13]}$ 。

天目湖流域位于苏浙皖三省交界, 属天目山余脉的丘陵地区,拥有大溪、沙河两座国家级大型水库, 是太 湖流域上游重要的水源涵养区。其中大溪水库集水面积 $90 \mathrm{~km}^{2}$, 水库面积近 $10 \mathrm{~km}^{2}$, 总库容达 1.13 亿 $\mathrm{m}^{3[14]}$; 沙河水库集水面积 $148.5 \mathrm{~km}^{2}$, 水库面积 $12 \mathrm{~km}^{2}$, 总库容 1.09 亿 $\mathrm{m}^{3[15]}$ 。这两座水库由调度河——沙溪河相 连,均是集饮用水源、农业灌溉、旅游和渔业生产等多功能于一体的大 (II) 型水库。近些年来, 随着地方经济 的发展, 两座水库的水质受到威胁, 面临着悬浮物增加、营养物质浓度升高、藻类大量繁殖、饮用水水源供水品 质下降等一系列水生态环境问题 ${ }^{[14,16-17]}$ 。鱼类作为水生生态系统中的顶级生物, 在维持生态系统平衡方面 发挥了重要作用 ${ }^{[18-19]}$, 但查阅文献资料, 发现关于大溪水库和沙河水库的鱼类调查资料胗胗无几, 关于其营 养结构的分析更是罕见。因此, 亟需开展大溪水库和沙河水库鱼类资源本底调查, 充分了解两座水库主要鱼 类群落组成及其营养结构的时空变化规律, 为资源养护和利用提供基本数据。本文利用碳、氮稳定同位素技 术研究探讨天目湖不同季度及不同库区主要鱼类群落食物网营养结构变化特征, 从而为进一步开展天目湖生 态渔业研究奠定基础。

\section{1 研究方法}

\section{1 样品采集}

本文研究水域为天目湖水域,包括大溪、沙河两座国家级大型水库。本研究分别于 2017 年 7 月、10 月和 2018 年 4 月在此开展采样工作 (见图 1), 在两个水库分别设置 2 个鱼类调查样点, 其中 S1 和 S2 位于大溪水 
库, S3 和 S4 位于沙河水库, 每个样点每次放置 4 条多 网目复合刺网 $(1.2 \mathrm{~cm} 、 2 \mathrm{~cm} 、 4 \mathrm{~cm} 、 6 \mathrm{~cm} 、 8 \mathrm{~cm} 、 10 \mathrm{~cm} 、 14$ $\mathrm{cm})$, 长、高分 $125 \mathrm{~m} 、 1.5 \mathrm{~m}$ 和 $250 \mathrm{~m} 、 3 \mathrm{~m}$ 两种及 3 条地 笼( 网目为 $1.6 \mathrm{~cm}$, 长、宽、高分别为 $10 \mathrm{~m} 、 0.4 \mathrm{~m} 、 0.4$ $\mathrm{m})$, 放置 $12 \mathrm{~h}$ 后收集所有渔获物, 鉴定到种。鱼类样 品采集后, 现场测定体长、体重等生物学数据, 体长精确 到 $0.01 \mathrm{~mm}$, 体重精确到 $0.1 \mathrm{~g}$ 。鱼类取背部白肌并冷冻 保存, 所有样品在 $-50{ }^{\circ} \mathrm{C}$ 真空冷冻 $48 \mathrm{~h}$, 用珠磨器研磨 成均匀粉末, 放人干燥器中保存待测。

\section{2 样品测定及表达}

样品送至国家海洋局第三海洋研究所进行同位素 值的测定, 仪器由同位素比率质谱仪 Delta $\mathrm{V}$ advantage) 与元素分析仪 (Flash EA 1112 HT) 耦合而成。碳氮稳 定性同位素测定分别采用国际标准物 VPDB（Vienna Pee Dee Belemnite) 和标准大气氮的同位素丰度作参 考。测定所用标准品为乙酰苯胺, 每个样品测定 3 个平 行样, 为保持实验结果的准确性和仪器的稳定性, 每 12 个样品插人一个标准品。分析结果表示为 $\delta^{13} \mathrm{C}$ 和 $\delta^{15} \mathrm{~N}^{[20]}$ :

$$
\delta X(\%)=\frac{R_{\text {sample }}-R_{\text {standard }}}{R_{\text {standard }}} \times 1000
$$

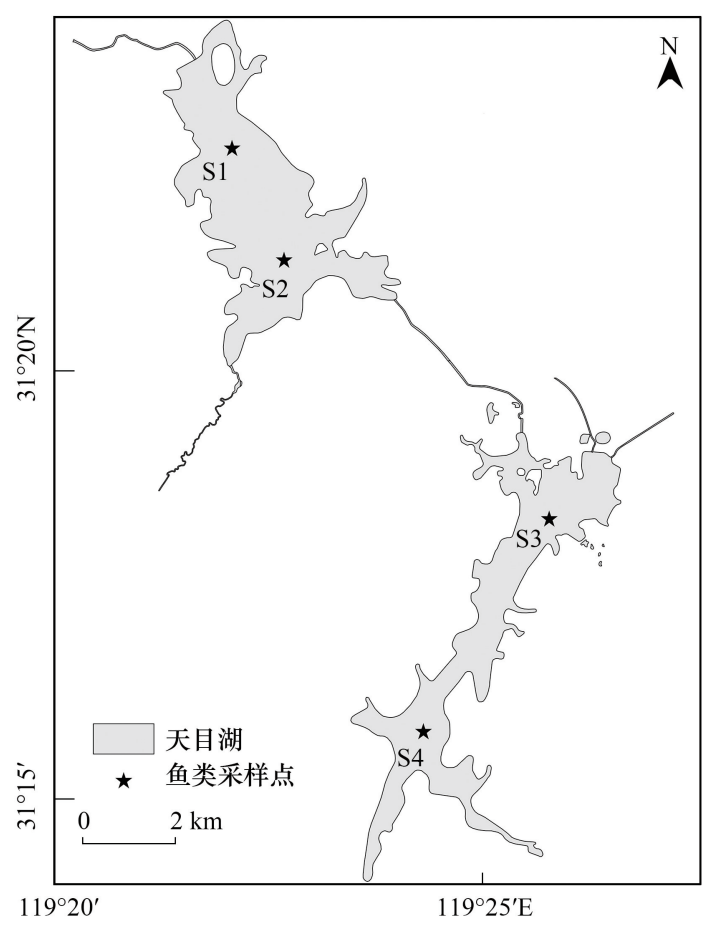

图 1 采样点分布图

Fig.1 Map of Daxi and Shahe Reservoir and location of sampling sites

$\mathrm{S} 1$ 和 $\mathrm{S} 2$ 为大溪水库的采样点, $\mathrm{S} 3$ 和 $\mathrm{S} 4$ 为沙河水库的采样点

其中 $X$ 为 ${ }^{15} \mathrm{~N}$ 或 ${ }^{13} \mathrm{C}, R$ 代表 ${ }^{15} \mathrm{~N} /{ }^{14} \mathrm{~N}$ 或者 ${ }^{13} \mathrm{C} /{ }^{12} \mathrm{C}, R_{\text {sample }}$ 表示样品的重轻同位素之比, $R_{\text {standard }}$ 是国际通用标准物的重轻同位素之比, 测量精度 $\delta^{13} \mathrm{C} \leqslant 0.2 \% 0, \delta^{15} \mathrm{~N} \leqslant$ $0.3 \%$ 。

鱼类优势种的优势度用 Pinkas 相对重要性指数( index of relative importance, IRI $)^{[21]}$ 表示:

$$
\mathrm{IRI}=(\mathrm{W} \%+N \%) \times F \%
$$

其中: $W \%$ 为该种鱼占总鱼类重量的百分比, $N \%$ 为该种鱼尾数占鱼类总尾数的百分比, $F \%$ 为该种鱼出现的次 数占调查总次数的百分比。

\section{3 数据整理统计分析}

Layman 等人所提到的 6 个参数的含义如下 ${ }^{[10]}$ :

(1) 碳值范围 $\mathrm{CR}\left(\delta^{13} \mathrm{C}\right.$ range ) : 具有最高 $\delta^{13} \mathrm{C}$ 值和最低 $\delta^{13} \mathrm{C}$ 值的两个物种之间的 $\delta^{13} \mathrm{C}$ 值距离, 可用来预 估鱼类的基础食物来源。

(2) 氮值范围 $\mathrm{NR}\left(\delta^{15} \mathrm{~N}\right.$ range $)$ : 具有最高 $\delta^{15} \mathrm{~N}$ 值和最低 $\delta^{15} \mathrm{~N}$ 值的两个物种之间的 $\delta^{15} \mathrm{~N}$ 值距离,一般用来 估计鱼类群落营养长度。

(3) 总面积 TA(Total area) 由所有物种在 $\delta^{13} \mathrm{C}-\delta^{15} \mathrm{~N}$ 双位图上组成的多边形面积,一般用来表示鱼类群落 生态位总区间。

(4) 平均离心距离 $\mathrm{CD}$ (Mean distance to centroid): 每一个物种到 $\delta^{13} \mathrm{C}-\delta^{15} \mathrm{~N}$ 双位图重心的平均欧氏距离, 可用于估计鱼类的营养多样性。

(5) 平均最邻近距离 MNND (Mean nearest neighbor distance) $: \delta^{13} \mathrm{C}-\delta^{15} \mathrm{~N}$ 双位图中每个物种与其最近的相 邻物种的平均欧式距离, 用以估计鱼类群落的整体密度。

(6) 最邻近距离标准差 $\operatorname{SDNND}$ (Standard deviation of nearest neighbor distance) : $\delta^{13} \mathrm{C}-\delta^{15} \mathrm{~N}$ 双位图上每个物 
种与其最近相邻物种欧式距离标准偏差的平均值,用于估计鱼类群落营养生态位分布范围均匀度。

以上各参数指标计算方法参考 Layman 等 ${ }^{[10]}$, 其值采用 $\mathrm{R}$ 软件进行计算。

有学者提出 ${ }^{[22]}$, TA 容易受鱼类种类数即样本量的影响, Jackson 等 ${ }^{[23]}$ 对 $\mathrm{TA}$ 进行了校正, 提出了标准椭 圆面积 SEAc,用以表示其核心生态位,其值采用 R 软件进行计算。

在 SPSS 软件中采用配对双样本 $\mathrm{t}$ 检验,对不同季节、不同区域的同种鱼类稳定性同位素进行差异分析。 图像处理采用 origin 软件和 $\mathrm{R}$ 软件完成。实验数据用平均数土标准差 $(\mathrm{Mean} \pm \mathrm{SD})$ 表示。

\section{2 结果与分析}

\section{1 天目湖主要鱼类群落结构组成及生态类群}

经咨询当地相关渔政单位, 2016-2017 年间, 大溪水库共放流鱼类约 4.8 万 $\mathrm{kg}$, 沙河水库约 8.8 万 $\mathrm{kg}$,主 要以鲢和鳙为主。本研究于 2017-2018 年在大溪水库共调查渔获物 28 种,隶属于 3 目 6 科 21 属; 沙河水库 共 29 种,隶属于 3 目 7 科 23 属。根据鱼类相对重要性指数 (IRI) 的计算结果, 将大于 1000 的确定为优势种 鱼类 ${ }^{[24]}$, 大溪水库的优势种 ( IRI > 1000$)$ 鱼类有 6 种, 分别为似鱎 (Toxabramis swinhonis)、鳙 (Aristichthys nobilis)、大鲑鱊 (Acheilognathus macropterus)、粲(Hemiculter leucisculus)、鲢(Hypophthalmichthys molitrix)、银鮈 (Squalidus argentatus); 沙河水库有 7 种, 分别为鲢、鳙、黄尾鲖 (Xenocypris davidi)、似鱎、粲、银鮈和蒙古鲌 (Culter mongolicus); 大溪水库常见种 $(100<\mathrm{IRI} \leqslant 1000)$ 有 12 种, 沙河水库有 11 种, 具体见表 1 。

表 1 大溪水库和沙河水库鱼类种类组成、优势度和生态类群

Table 1 Species composition, IRI and ecological types of fish community in Daxi and Shahe Reservoir

\begin{tabular}{|c|c|c|c|c|c|c|}
\hline $\begin{array}{l}\text { 物种 } \\
\text { Species }\end{array}$ & $\begin{array}{l}\text { 代码 } \\
\text { Code }\end{array}$ & $\begin{array}{c}\text { 体长范围 } \\
\text { Body length } \\
\text { range }\end{array}$ & $\begin{array}{c}\text { 体重范围 } \\
\text { Weight range }\end{array}$ & $\begin{array}{c}\text { IRI } \\
\text { (大溪水库 } \\
\text { Daxi } \\
\text { Reservoir) }\end{array}$ & $\begin{array}{c}\text { IRI } \\
\text { ( 沙河水库 } \\
\text { Shahe } \\
\text { Reservoir) }\end{array}$ & $\begin{array}{c}\text { 生态类群 } \\
\text { Ecological types }\end{array}$ \\
\hline 似鱎 Toxabramis swinhonis & TS & $80.88-135.36$ & $6.0-25.9$ & 4605 & 1538 & $O, L, R$ \\
\hline 鲢 Hypophthalmichthys molitrix & HMV & $250.5-505$ & $297.0-2447.0$ & 1552 & 2875 & $\mathrm{~F}, \mathrm{U}, \mathrm{P}$ \\
\hline 鳙 Aristichthys nobilis & AN & $169.21-710$ & $105.2-6158.0$ & 3040 & 2259 & $\mathrm{~F}, \mathrm{U}, \mathrm{P}$ \\
\hline 大鳍鱊 Acheilognathus macropterus & $\mathrm{AM}$ & $50.53-122.84$ & $3.2-43.2$ & 2617 & 364 & $\mathrm{O}, \mathrm{U}, \mathrm{R}$ \\
\hline 粲 Hemiculter leucisculus & HL & $93.05-157.14$ & $7.5-40.6$ & 1819 & 1494 & $\mathrm{O}, \mathrm{U}, \mathrm{R}$ \\
\hline 银鮈 Squalidus argentatus & $\mathrm{SA}$ & $84.495-138.78$ & $9.3-36.1$ & 1421 & 1206 & $\mathrm{O}, \mathrm{L}, \mathrm{R}$ \\
\hline 黄尾鲖 Xenocypris davidi & $\mathrm{XD}$ & $227.07-280.69$ & $183.0-385.0$ & 12 & 2000 & $\mathrm{O}, \mathrm{L}, \mathrm{R}$ \\
\hline 蒙古鲌 Culter mongolicus & CM & $104.38-215.88$ & $14.1-114.5$ & 302 & 1175 & $\mathrm{C}, \mathrm{U}, \mathrm{R}$ \\
\hline 鲫 Carassius auratus & CAL & $129.21-245$ & $89.0-395.0$ & 889 & 616 & $\mathrm{O}, \mathrm{L}, \mathrm{R}$ \\
\hline 达氏鲌 Culter dabryi & CD & $87.16-196.73$ & $6.4-82.5$ & 271 & 673 & $\mathrm{C}, \mathrm{U}, \mathrm{R}$ \\
\hline 鲹 Siniperca chuatsi & $\mathrm{SC}$ & $159.67-406.41$ & $87.5-1709.8$ & 465 & 222 & $\mathrm{C}, \mathrm{L}, \mathrm{R}$ \\
\hline 黑鮱鳈 Sarcocheilichthys nigripinnis & $\mathrm{SN}$ & $60.21-105.98$ & $3.7-25.4$ & 175 & 443 & $\mathrm{O}, \mathrm{L}, \mathrm{R}$ \\
\hline 花鳃 Hemibarbus maculatus & HMB & $182.59-267.28$ & $60.0-298.6$ & 219 & 461 & $\mathrm{C}, \mathrm{L}, \mathrm{R}$ \\
\hline 华鳈 Sarcocheilichthys sinensis & SS & $76.33-158.53$ & $8.2-95.6$ & 87 & 212 & $\mathrm{C}, \mathrm{L}, \mathrm{R}$ \\
\hline 黄颡鱼 Pelteobagrus fulvidraco & $\mathrm{PF}$ & $132.51-212.32$ & $37.6-137.5$ & 219 & 171 & $\mathrm{O}, \mathrm{B}, \mathrm{R}$ \\
\hline 鲤 Cyprinus carpio & $\mathrm{CC}$ & $335-493$ & $936.0-2327.0$ & 244 & 44 & $\mathrm{O}, \mathrm{B}, \mathrm{R}$ \\
\hline 翘嘴鲌 Culter alburnus Basilewsky & $\mathrm{CAB}$ & $100.31-304.27$ & $9.5-314.0$ & 74 & 276 & $\mathrm{C}, \mathrm{U}, \mathrm{R}$ \\
\hline 似刺鳊鮈 Paracanthobrama guichenoti & PG & $77.98-240.32$ & $8.2-274.4$ & 605 & - & $\mathrm{O}, \mathrm{L}, \mathrm{R}$ \\
\hline 兴凯鱊 Acheilognathus chankaensis & $\mathrm{AC}$ & $29.38-85.15$ & $0.7-14.8$ & 121 & 99 & $\mathrm{O}, \mathrm{U}, \mathrm{R}$ \\
\hline 中华鳑鲏 Rhodeus sinensis & RS & $30.83-51.96$ & $0.6-3.1$ & 156 & 189 & $\mathrm{O}, \mathrm{B}, \mathrm{R}$ \\
\hline 细鳞鲖 Xenocypris microlepis & XM & $181.7-280$ & $117.2-408.0$ & - & 857 & $\mathrm{O}, \mathrm{L}, \mathrm{R}$ \\
\hline 贝氏粲 Hemiculter bleekeri & HB & $94.62-120.35$ & $10.6-18.4$ & 106 & - & $\mathrm{O}, \mathrm{U}, \mathrm{R}$ \\
\hline 大眼鳜 Siniperca kneri & SK & $123.52-218.45$ & $38.7-227.5$ & 70 & 95 & $\mathrm{C}, \mathrm{L}, \mathrm{R}$ \\
\hline 麦穗鱼 Pseudorasbora parva & PP & $48.03-84.57$ & $1.7-11.0$ & 71 & 95 & $O, L, R$ \\
\hline
\end{tabular}




\begin{tabular}{|c|c|c|c|c|c|c|}
\hline $\begin{array}{l}\text { 物种 } \\
\text { Species }\end{array}$ & $\begin{array}{l}\text { 代码 } \\
\text { Code }\end{array}$ & $\begin{array}{c}\text { 体长范围 } \\
\text { Body length } \\
\text { range }\end{array}$ & $\begin{array}{c}\text { 体重范围 } \\
\text { Weight range }\end{array}$ & $\begin{array}{c}\text { IRI } \\
\text { (大溪水库 } \\
\text { Daxi } \\
\text { Reservoir) }\end{array}$ & $\begin{array}{c}\text { IRI } \\
\text { (沙河水库 } \\
\text { Shahe } \\
\text { Reservoir) }\end{array}$ & $\begin{array}{c}\text { 生态类群 } \\
\text { Ecological types }\end{array}$ \\
\hline 子陵吻虾虎鱼 Rhinogobius giurinus & $\mathrm{RG}$ & $27.81-55.56$ & $0.4-2.5$ & 53 & 12 & $\mathrm{C}, \mathrm{B}, \mathrm{R}$ \\
\hline 红鰙原鲌 Cultrichthys erythropterus & CE & $107.17-146.28$ & $14.0-36.4$ & - & 11 & $\mathrm{C}, \mathrm{U}, \mathrm{R}$ \\
\hline 长须黄滪鱼 Pelteobagrus eupogon & $\mathrm{PE}$ & $216.86-216.86$ & $94.8-94.8$ & 6 & - & $\mathrm{O}, \mathrm{B}, \mathrm{R}$ \\
\hline 蛇鮈 Saurogobio dabryi & SD & $49.75-60.21$ & $1.8-3.1$ & 5 & 5 & $\mathrm{O}, \mathrm{B}, \mathrm{R}$ \\
\hline 泥鲉 Misgurnus anguillicaudatus & MA & $91.84-139.82$ & $25.7-50.6$ & 4 & 21 & $\mathrm{O}, \mathrm{B}, \mathrm{R}$ \\
\hline 鲇 Parasilurus asotus & $\mathrm{PA}$ & $214.72-214.72$ & $102.7-102.7$ & - & 4 & $\mathrm{C}, \mathrm{B}, \mathrm{R}$ \\
\hline 大鳞副泥鱾 Paramisgurnus dabryanus & PD & $104.19-104.19$ & $10.8-10.8$ & - & 2 & $\mathrm{O}, \mathrm{B}, \mathrm{R}$ \\
\hline 河川沙塘鳢 Odontobutis obscurus & OO & $79.93-132.98$ & $11.0-45.8$ & 6 & 3 & $\mathrm{C}, \mathrm{B}, \mathrm{R}$ \\
\hline
\end{tabular}

$\mathrm{U}$ : 中上层; L: 中下层; B : 底层; P : 江湖半洄游性; R : 淡水定居性; C : 肉食性; O : 杂食性; F : 滤食性; “-”说明没有出现

从鱼类群落组成结构来看, 大溪水库和沙河水库有 约 78\%的物种相同,均以鲤科鱼类为主; 从鱼类摄食类 群分析显示,大溪水库和沙河水库均以杂食性鱼类为主 (大溪水库: $60.71 \%$, 沙河水库: $55.17 \%$ ), 肉食性鱼类为 辅 (大溪水库: $32.14 \%$,沙河水库: $37.93 \%$ ), 滤食性鱼类 最少 (均为 2 种); 从鱼类栖息水层来看,两个水库不同 栖息水层的鱼类分布较为均匀; 从鱼类洄游类型分析, 两个水库均以定居性鱼类为主, 仅鲢和鳙为江湖半洄游 性鱼类(图 2)。

2.2 碳氮稳定性同位素组成及其时空变化特征

稳定同位素结果显示, 大溪水库主要鱼类的平均 $\delta^{13}$ $\mathrm{C}$ 值在 $-31.75 \% 0-21.82 \%$ 之间, $\delta^{15} \mathrm{~N}$ 值在 $8.48 \% 0-$ $15.77 \%$ 之间; 沙河水库平均 $\delta^{13} \mathrm{C}$ 值在 $-30.16 \%$ $-19.27 \%$ 之间, $\delta^{15} \mathrm{~N}$ 值在 $4.20 \%$ - $16.55 \%$ 。间。

选取同季节同种类不同区域的鱼类碳、氮稳定同位

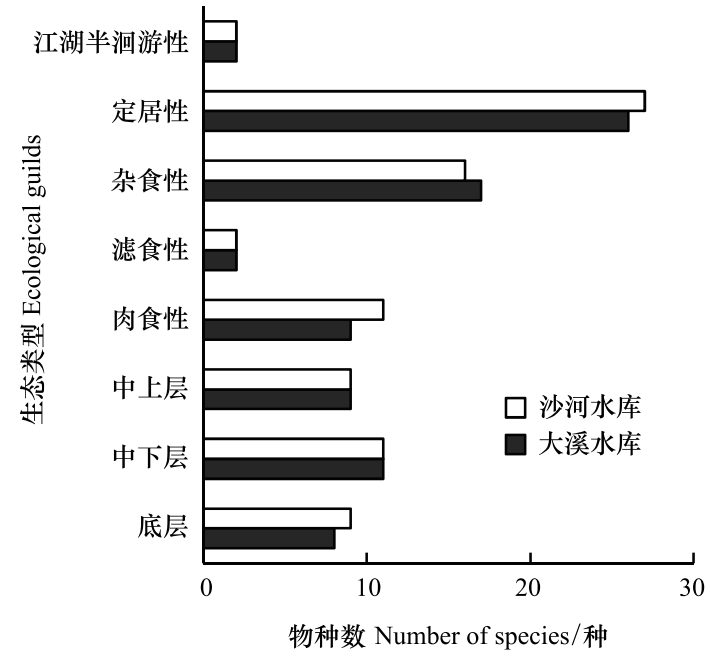

图 2 大溪水库和沙河水库鱼类群落生态类群

Fig.2 Fish ecological types of Daxi and Shahe Reservoir 素值进行空间差异比较,数据均符合正态分布。配对双样本 $\mathrm{t}$ 检验结果表明,春季、夏季、秋季大溪水库和沙 河水库 $\delta^{13} \mathrm{C}$ 值均有极显著差异 $(P<0.01)$, 春季、夏季 $\delta^{15} \mathrm{~N}$ 值均没有显著差异 $(P>0.05)$, 而秋季表现为极显著 差异 $(P<0.01)$ 。选取同区域同种类不同季节的鱼类碳、氮稳定同位素值进行季节差异比较。配对双样本 $t$ 检 验结果表明, 大溪水库鱼类 $\delta^{13} \mathrm{C}$ 值春季、夏季和秋季没有显著差异 $(P>0.05)$, 而沙河水库鱼类 $\delta^{13} \mathrm{C}$ 值春季和 夏季、夏季和秋季间均有显著差异 $(P<0.05)$, 但春、秋季无显著差异 $(P>0.05)$; 大溪水库 $\delta^{15} \mathrm{~N}$ 值三个季度间 均有显著差异 $(P<0.05)$, 而沙河水库除春季和夏季有显著差异外 $(P<0.01)$, 其他的季度间没有显著差异 $(P>$ $0.05)$, 具体见表 2 。

2.3 鱼类群落营养结构变化特征

天目湖大溪水库和沙河水库在不同季度内主要鱼类稳定同位素值见附录 1,坐标图如图 3 和图 4 所示。 其中, 大溪水库春季位于多边形顶点的鱼类分别为兴凯鱊 (Acheilognathus chankaensis)、唋、长须黄颡鱼 (Pelteobagrus eupogon)、达氏鲌(Culter dabryi)、鳜(Siniperca chuatsi)、子陵吻虾虎鱼(Rhinogobius giurinus),夏 季分别为鲢、黄颡鱼 (Pelteobagrus fulvidraco)、趐嘴鲌(Culter alburnus)、鲊、子陵吻虾虎鱼、大鰙鱊,秋季为黄尾 鲖、鲢、麦穗鱼 (Pseudorasbora parva)、鲫 (Carassius auratus)、花鳃 (Hemibarbus maculatus)、鲊; 沙河水库春季位 于多边形顶点的鱼类分别为鲇 (Parasilurus asotus)、细鳞鲖 (Xenocypris microlepis)、蒙古鲌、翘嘴鲌、大眼鱑 
(Siniperca kneri)、兴凯鱊,夏季为大鳞副泥鲀(Paramisgurnus dabryanus)、鲢、似鱎、黄颡鱼、达氏鲌、花鳃、河川 沙塘鳢 (Odontobutis obscurus) 、兴凯鱊, 秋季为鲫、细鳞鲖、粲、似鱎、蒙古鲌、黒鯺鳈 ( Sarcocheilichthys nigripinnis)。

表 2 同种鱼类碳氮稳定同位素值时空差异分析

Table $2 \delta^{13} \mathrm{C}$ and $\delta^{15} \mathrm{~N}$ value comparison of the same selected species

\begin{tabular}{|c|c|c|c|c|c|c|c|c|c|c|}
\hline \multirow{2}{*}{$\begin{array}{l}\text { 对比项 } \\
\text { Comparison items }\end{array}$} & \multirow{2}{*}{$\begin{array}{c}\text { 分类 } \\
\text { Category }\end{array}$} & \multirow{2}{*}{$\begin{array}{l}\text { 种类数 } \\
\text { Number } \\
\text { of species }\end{array}$} & \multicolumn{4}{|c|}{$\delta^{13} \mathrm{C}$} & \multicolumn{4}{|c|}{$\delta^{15} \mathrm{~N}$} \\
\hline & & & $\begin{array}{l}\text { 均数 } \\
\text { Mean }\end{array}$ & $\begin{array}{l}\text { 检验值 } \\
\mathrm{t} \text { value }\end{array}$ & $d f$ & $\begin{array}{l}\text { 显著性 } \\
\text { Sig. }(P)\end{array}$ & $\begin{array}{l}\text { 均数 } \\
\text { Mean }\end{array}$ & $\begin{array}{l}\text { 检验值 } \\
\mathrm{t} \text { value }\end{array}$ & $d f$ & $\begin{array}{l}\text { 显著性 } \\
\text { Sig. }(P)\end{array}$ \\
\hline 大溪-沙河 & 春 & 16 & 2.005 & 7.368 & 39 & 0.000 & -0.001 & -0.003 & 39 & 0.998 \\
\hline Daxi Reservoir to & 夏 & 15 & 1.161 & 5.463 & 37 & 0.000 & -0.29 & -1.479 & 37 & 0.148 \\
\hline Shahe Reservoir & 秋 & 17 & 1.735 & 3.82 & 35 & 0.001 & -2.219 & -5.997 & 35 & 0.000 \\
\hline 春-夏 & 大溪 & 15 & 0.442 & 1.439 & 30 & 0.160 & -0.845 & -2.683 & 30 & 0.012 \\
\hline Spring to summer & 沙河 & 18 & -1.685 & -4.549 & 42 & 0.000 & -0.882 & -2.974 & 42 & 0.005 \\
\hline 春-秋 & 大溪 & 17 & 0.419 & 1.293 & 32 & 0.205 & 0.866 & 2.525 & 32 & 0.017 \\
\hline Spring to autumn & 沙河 & 17 & -0.042 & -0.107 & 43 & 0.915 & -0.338 & -0.949 & 43 & 0.348 \\
\hline 夏-秋 & 大溪 & 15 & -0.100 & -0.518 & 34 & 0.608 & 1.97 & 9.53 & 34 & 0.000 \\
\hline Summer to autumn & 沙河 & 18 & 0.732 & 2.35 & 46 & 0.023 & 0.3 & -0.88 & 46 & 0.384 \\
\hline
\end{tabular}

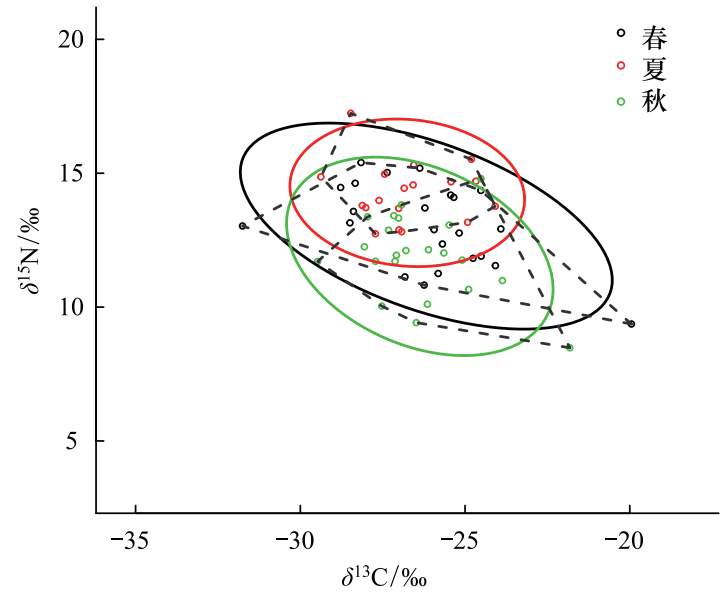

图 3 大溪水库不同季度内主要鱼类碳氮稳定同位素分布图

Fig.3 $\delta^{13} \mathrm{C}$ and $\delta^{15} \mathrm{~N}$ value distribution of key fishes during different seasons in Daxi Reservoir

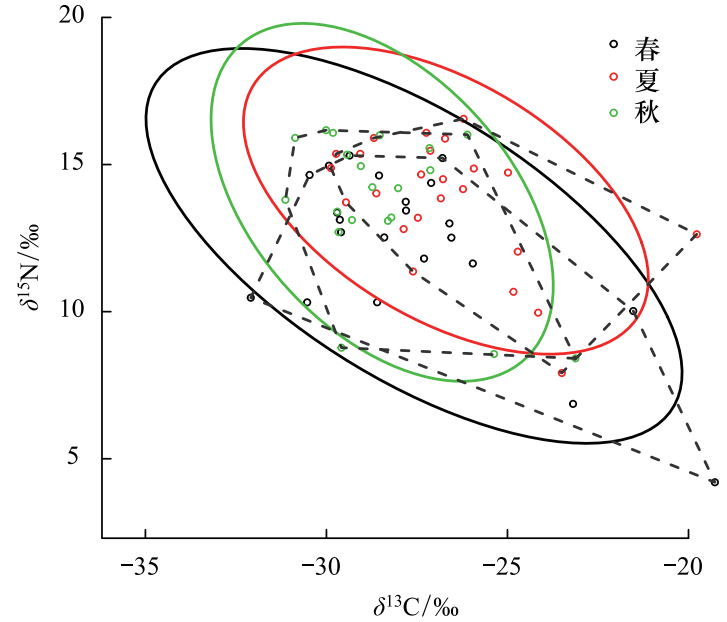

图 4 沙河水库不同季度内主要鱼类碳氮稳定同位素分布图

Fig.4 $\delta^{13} \mathrm{C}$ and $\delta^{15} \mathrm{~N}$ value distribution of key fishes during different seasons in Shahe Reservoir

基于 $\delta^{13} \mathrm{C}-\delta^{15} \mathrm{~N}$ 的双位图,计算出稳定同位素生态位指标值,如表 3 所示。区域分析结果显示,三个季度 内沙河水库常见鱼类的基础食物来源 $(\mathrm{CR}) 、$ 营养长度 $(\mathrm{NR}) 、$ 群落生态位总区间 ( TA)、核心生态位 ( SEAc)、 营养多样性 $(C D)$ 、常见鱼类群落的整体密度 (MNND) 和群落营养生态位分布均匀度 (SDNND) 均高于大溪水 库鱼类群落的生态位指标。季度分析结果显示, 大溪水库鱼类群落的 6 个生态位指标自春季至秋季呈现先下 降再上升的趋势, 而沙河水库呈现春季高于夏季高于秋季的趋势。

\section{3 讨论}

3.1 天目湖鱼类群落组成特征

生物多样性的保护是水生生态系统得以维持稳定的基础,而物种多样性保护是生物多样性保护的核心， 
它既能体现生物与环境之间的复杂关系, 又能体现生物资源的丰富性 ${ }^{[25]}$ 。栖息于淡水中的鱼类种类众 多 ${ }^{[26]}$, 它们通过捕食关系调节水体中其他生物的丰度, 从而对水生生态系统结构和功能产生重要的影响 ${ }^{[27]}$ 。 一般来说, 生态系统中物种数越多, 捕食关系也就更加多样化, 所形成的食物链和食物网也更为复杂 ${ }^{[28]}$ 。张 波等认为群落多样性的变化一般会直接影响群落食物网的结构和功能, 莱州湾鱼类群落结构组成日趋简单 化, 平均营养级明显下降也验证了这一点 ${ }^{[29-30]}$ 。与千岛湖类似 ${ }^{[31-32]}$, 大溪水库和沙河水库鱼类群落存在湖泊 化规律, 遵循鱼类的溪流性本底分布逐步发展为湖泊化效应分布, 呈现出以湖泊定居性鱼类和鲤科鱼类为主 的特征, 凶猛性鱼类以湖泊中常出现的蒙古鲌、翘嘴鮊、鲭等所替代。大溪水库和沙河水库鱼类分布较为均 匀,但鱼类种类数仍偏少, 食物网结构仍较为简单。研究表明, 天目湖周边农业的快速发展,地表径流、水土流 失等将大量的农业面源污染物带人水体, 造成水体水质逐渐变差 ${ }^{[33-34]}$, 这可能会引起鱼类种类组成发生改 变。近些年, 当地政府为了保护天然水域渔业资源, 多次采取多品种、多比例的放流苗种组合形式开展放流活 动, 同时对天目湖实行全域全年封湖禁渔等措施。从本研究结果来看, 大溪水库和沙河水库除了历史资料中 出现的鲢、鳙外, 还出现了黄尾鲖、似鱎、粲、银鮈、蒙古鲌等多个优势种, 说明这些措施可能起到了一定的保护 效果,建议继续采取相应的措施进行渔业资源保护。

表 3 大溪水库和沙河水库不同季度内常见鱼类群落特征值

Table 3 Values of fish communities in different seasons of Daxi and Shahe Reservoir

\begin{tabular}{|c|c|c|c|c|c|c|}
\hline & \multicolumn{3}{|c|}{ 大溪水库 Daxi Reservoir } & \multicolumn{3}{|c|}{ 沙河水库 Shahe Reservoir } \\
\hline & 春季 & 夏季 & 秋季 & 春季 & 夏季 & 秋季 \\
\hline & Spring & Summer & Autumn & Spring & Summer & Autumn \\
\hline $\mathrm{CR}$ & 11.80 & 5.29 & 7.66 & 12.82 & 10.10 & 8.01 \\
\hline NR & 6.03 & 4.50 & 6.32 & 11.10 & 8.64 & 7.76 \\
\hline TA & 30.74 & 14.80 & 25.85 & 64.59 & 45.57 & 43.95 \\
\hline SEAc & 10.16 & 5.45 & 7.79 & 20.95 & 13.76 & 14.09 \\
\hline CD & 2.31 & 1.58 & 1.86 & 3.14 & 2.58 & 2.47 \\
\hline MNND & 0.89 & 0.72 & 0.84 & 1.25 & 1.00 & 0.97 \\
\hline SDNND & 1.03 & 0.60 & 0.70 & 1.21 & 0.93 & 0.92 \\
\hline
\end{tabular}

$\mathrm{CR}$ : 碳值范围 $\delta^{13} \mathrm{C}$ range; $\mathrm{NR}$ : 氮值范围 $\delta^{15} \mathrm{~N}$ range; $\mathrm{TA}$ : 总面积 Total area; $\mathrm{SEAc}$ : 标准椭圆面积; $\mathrm{CD}$ : 平均离心距离 Mean distance to centroid; MNND: 平均最邻近距离 Mean nearest neighbor distance; SDNND : 最邻近距离标准差 Standard deviation of nearest neighbor distance

\section{2 鱼类 $\delta^{13} \mathrm{C}$ 和 $\delta^{15} \mathrm{~N}$ 值的时空差异}

水生生物的杂食性和营养塑性普遍存在,使得同种生物在不同时间和空间其食物组成也不相同。研究指 出,鱼类的 $\delta^{13} \mathrm{C}$ 值和 $\delta^{15} \mathrm{~N}$ 值与水域生境及旿料生物的变化有关,初级食物源通过食物网内的捕食关系对鱼类 等消费者体内的同位素比值产生影响, 不同生境及人类活动的扰动导致鱼类营养级和食物网结构存在较大不 确定性 ${ }^{[35]}$ 。李忠义等人发现生物资源种类的营养级存在空间和生物种类的不同,显示出渔业生物营养位置 对生境差异的响应 ${ }^{[36]}$ 。一般情况下, 我们以 $\delta^{13} \mathrm{C}$ 值来指示食物源, 本研究中三个季度内大溪水库和沙河水库 相同鱼类的 $\delta^{13} \mathrm{C}$ 值呈现出极显著的差异，大溪水库鱼类季度差异不显著，而沙河水库鱼类季度间差异明显， 说明同时期的两个水库初级食物源也存在比较明显的差异, 同区域内大溪水库初级食物源的同位素值变化不 明显。 $\delta^{15} \mathrm{~N}$ 值时空变化规律不明显, 这可能与水库周围农业活动和人类活动的不确定性有关。周九州 (2010) 等人提出, 农田径流带人地表水的氮占人类活动排人水体氮的 $51 \%$,施肥地区氮素流失量比不施肥地 区高 3.1 倍 ${ }^{[37]}$ 。调查显示, 茶园是天目湖丘陵山地最主要的农业开发类型, 水库周边茶园面积广 (茶园面积 占 $9.3 \%$ ，植被覆盖度高达 70\%, 施肥强度很高, 尤其是春季茶叶集中施肥期, 茶园坡度大、水土流失严重、人 湖流程短等问题导致污染物削减比例低, 大量的外源性营养物质随地表径流被输送至水库, 导致水体氮浓度 大大增加,一场春雨甚至能使水库总氮浓度增加 1 倍 ${ }^{[38-39]}$ 。因此, 水库的外源污染物浓度与是否处于集中施 肥期、降雨量多少、降雨时间等多因素相关,存在较大的不确定性。 


\section{3 鱼类群落营养结构变化特征}

研究指出,在 $\delta^{13} \mathrm{C}-\delta^{15} \mathrm{~N}$ 双位图中,位于凸多边形顶点的生物对维持水生食物网的稳定起到了重要的作 用, 当它们其中某些种类在这个群落消失或者变动, 会导致 $\mathrm{CR} 、 \mathrm{NR} 、 \mathrm{TA}$ 等多个参数的变化, 进而影响整个鱼 类群落的营养结构 ${ }^{[40]}$ 。本研究中位于多边形顶点的生物主要为顶级肉食性捕食者 (如鲖、蒙古鲌、翅嘴鲌 等)、杂食性鱼类(如粲、鲫、大鳞副泥鳅等) 以及食浮游生物的滤食性鱼类(如鲢)等,因此, 应尽可能的多关注 这些生物种群的变化,进而合理开发渔业资源、维持生态系统长期稳定发展。

营养关系是群落内各生物体之间最重要的联系, 是了解生态系统能量流动的核心,也是群落赖以生存的 基础 ${ }^{[41]}$ 。调查表明, 沙河水库 $\mathrm{CR} 、 \mathrm{NR} 、 \mathrm{TA} 、 \mathrm{SEAc}$ 和 $\mathrm{CD}$ 值均高于大溪水库,且两个水库的鱼类群落指标值均 为春季最高, 这说明沙河水库春季食物网较其他季节、较大溪水库的初级食物源更加丰富 ${ }^{[10]}$, 食物链更长, 营 养层次更多,核心生态位宽幅更低,鱼类食物网营养级多样性的总程度较高, 营养生态位均匀度较低, 这可能 与其周围广泛分布的茶园、旅游区和居民区密集等有关。天目湖周边茶园区域分布统计结果显示, 有 $70 \%$ 左 右的茶园集中于大溪水库中下游山区、沙河水库西岸临湖岸破、沙河水库中下游东部山区,这些区域居民集中 分布 ${ }^{[42-46]}$, 而由此产生的大量生活污水与农业废水的排人严重影响了水库水质及生物的生长, 从而对生物体 内的同位素比值产生影响。Layman 等人 ${ }^{[10,47-48]}$ 指出, MNND 值和 SDNND 值较低意味着食物网的营养冗余程 度较高, 而大溪水库 MNND 值和 SDNND 值均比沙河水库更低, 这表明大溪水库生态系统抵御外界干扰能力 较强,生态系统的稳定性也更高。

\section{4 结论}

基于稳定同位素技术,本研究初步分析了春季、夏季和秋季期间,天目湖大溪水库和沙河水库主要鱼类的 营养结构,结果表明: 天目湖两个水库的鱼类群落组成结构相似,各栖息水层生物种类分布较为均匀,鱼类食 物网结构较为简单, 呈现出以湖泊定居性鱼类和鲤科鱼类为主的特征; 大溪水库食物网的初级食物源季度变 化不大, 而沙河水库有着明显的季度差异, 且各季度内沙河水库较大溪水库初级食物源更加丰富, 食物链更 长, 营养层次更多, 核心生态位宽幅更低, 鱼类食物网营养级多样性的总程度较高, 营养生态位均匀度较低, 其 穴余程度较低, 说明其水生生态系统抗外界干扰能力更弱, 这可能与周边茶园、旅游区和居民区密集分布有 关。因此,建议各级相关政府及科研机构更多关注沙河水库渔业资源及生态系统的变化,加强管理,从而能够 确保沙河水库渔业资源的生态发展与可持续利用。

\section{参考文献 (References) :}

[ 1 ] 郭依泉, 赵志模. 群落食物网间的相似性测度. 生态学杂志, 1992, 11(3) : 65-68.

[2] 张欢, 何亮, 张培育, 沙永翠, 徐军. 食物链长度理论研究进展. 生态学报, 2013, 33(24): 7630-7643.

[ 3 ] Post D M, Pace M L, Hairston Jr N G. Ecosystem size determines food-chain length in lakes. Nature, 2000, 405( 6790) : $1047-1049$.

[ 4 ] 吕振波, 李凡, 徐炳庆, 王波. 黄海山东海域春、秋季鱼类群落多样性. 生物多样性, 2012, 20(2) : 207-214.

[ 5 ] 宁加佳, 杜飞雁, 王雪辉, 王亮根, 谷阳光, 李亚芳. 南沙群岛西南部陆架区底层鱼类营养结构研究. 海洋与湖沼, 2016, 47 (2): 468- 475 .

[ 6 ] Sheaves M. Scale-dependent variation in composition of fish fauna among sandy tropical estuarine embayments. Marine Ecology Progress Series, 2006, 310: 173-184.

[ 7 ] Post D M. Using stable isotopes to estimate trophic position: models, methods, and assumptions. Ecology, 2002, 83(3) : 703-718.

[ 8 ] West J B, Bowen G J, Cerling T E, Ehleringer J R. Stable isotopes as one of nature's ecological recorders. Trends in Ecology \& Evolution, 2006, $21(7): 408-414$.

[ 9 ] Newsome S D, Del Rio C M, Bearhop S, Phillips D L. A niche for isotopic ecology. Frontiers in Ecology and the Environment, 2007, 5( 8): 429-436.

[10] Layman C A, Arrington D A, Montaña C G, Post D M. Can stable isotope ratios provide for community-wide measures of trophic structure? Ecology, 2007, 88(1): 42-48.

[11] Layman C A, Quattrochi J P, Peyer C M, Allgeier J E. Niche width collapse in a resilient top predator following ecosystem fragmentation. Ecology 
Letters, $2007,10(10): 937-944$.

[12] Quevedo M, Svanbäck R, Eklöv P. Intrapopulation niche partitioning in a generalist predator limits food web connectivity. Ecology, 2009, 90(8) : 2263-2274.

[13] Delong M D, Thorp J H, Thoms M C, McIntosh L M. Trophic niche dimensions of fish communities as a function of historical hydrological conditions in a Plains River. River Systems, 2011, 19(3): 177-187.

[14] 柏祥, 陈开宁, 黄蔚, 任艳芹, 陈效民. 大溪水库水体营养现状分析. 海洋湖沼通报, 2010, (3) : 115-120.

［15］曾春芬, 黄文钥, 王伟霞, 朱广伟. 天目湖溶解氧分布特征及环境影响因子. 长江流域资源与环境, 2010，19(4)：445-451.

[16] 张运林, 陈伟民，杨顶田，黄文铅，江晶. 天目湖 2001-2002 年环境调查及富营养化评价. 长江流域资源与环境，2005，14(1)：99-103.

[17］高永霞, 朱广伟, 贺申冉, 王芳. 天目湖水质演变及富营养化状况研究. 环境科学, 2009, 30(3): 673-679.

［18］高欣, 丁森, 张远，马淑芹, 刘思思, 孟伟. 鱼类生物群落对太子河流域土地利用、河岸带栖息地质量的响应. 生态学报, 2015, 35(21)： 7198-7206.

[19］吴丹, 卢奥然, 田爽, 殷旭旺, 张远, 徐宗学. 浑太河鱼类群落多样性及生境适宜性量化分析. 中国环境科学, 2019, 39(11): 4875-4885.

[20] McKinney C R, McCrea J M, Epstein S, Allen H A, Urey H C. Improvements in mass spectrometers for the measurement of small differences in isotope abundance ratios. Review of Scientific Instruments, 1950, 21(8) : 724-730.

[21] Pinkas L, Oliphant M S, Iverson I L K. Food habits of albacore, bluefin tuna, and bonito in California waters. Fish Bulletin, 1971, 152:1-105.

[22] Jackson A L, Inger R, Bearhop S, Parnell A. Erroneous behaviour of MixSIR, a recently published Bayesian isotope mixing model: a discussion of Moore \& Semmens (2008). Ecology Letters, 2009, 12(3): E1-E5.

[23] Jackson A L, Inger R, Parnell A C, Bearhop S. Comparing isotopic niche widths among and within communities: SIBER-Stable Isotope Bayesian Ellipses in R. Journal of Animal Ecology, 2011, 80(3) : 595-602.

[24］李凡, 徐炳庆, 吕振波, 王田田. 莱州湾鱼类群落优势种生态位. 生态学报, 2018, 38(14) : 5195-5205.

[25］魏辅文, 聂永刚, 苗海霞, 路浩, 胡义波. 生物多样性丧失机制研究进展. 科学通报, 2014, 59(6) : 430-437.

[26] Lundberg J G, Kottelat M, Smith G R, Stiassny M L J, Gill A C. So many fishes, so little time: an overview of recent ichthyological discovery in Continental Waters. Annals of the Missouri Botanical Garden, 2000, 87(1):26-62.

[27] Villéger S, Brosse S, Mouchet M, Mouillot D, Vanni M J. Functional ecology of fish: current approaches and future challenges. Aquatic Sciences, 2017, 79(4): 783-801.

[28] 程馨雨, 陶捐, 武瑞东, 陈礼强, 丁城志. 淡水鱼类功能生态学研究进展. 生态学报, 2019, 39(3): 810-822.

[29] Shan X J, Sun P F, Jin X S, Li X S, Dai F Q. Long-term changes in fish assemblage structure in the Yellow River Estuary Ecosystem, China. Marine and Coastal Fisheries, 2013, 5(1):65-78.

[30］张波，吴强，金显仕. 1959-2011 年莱州湾渔业资源群落食物网结构的变化. 中国水产科学, 2015, 22(2): 278-287.

[31］侯文华, 胡梦红, 刘其根. 千岛湖刺网渔获物中鱼类群落结构及多样性特征分析. 上海海洋大学学报, 2014, 23(6): 826-833.

[32］郝雅宾, 刘金殿, 郭爱环, 张爱菊, 原居林, 练青平, 顾志敏. 千岛湖国家级水产种质资源保护区 (梓桐核心区) 鱼类群落结构. 上海海洋 大学学报, 2019, 28(4): 587-596.

[33] 才亚芹, 李恒鹏, 韩莹. 基于土地利用变化预测的天目湖水源地污染风险评价//2014 中国环境科学学会学术年会论文集. 成都: 中国环 境科学学会, 2014 .

[34] 伊平, 张否, 包健. 天目湖流域农业面源污染控制研究. 污染防治技术, 2008, 21(6)：38-40, 43-43.

[35] Zhang Y, Ding S, Bentsen C N, Ma S Q, Jia X B, Meng W. Differences in stream fish assemblages subjected to different levels of anthropogenic pressure in the Taizi River catchment, China. Ichthyological Research, 2015, 62(4): 450-462.

[36] 李忠义, 左涛, 戴芳群, 金显仕. 运用稳定同位素技术研究长江口及南黄海水域春季拖网渔获物的营养级. 中国水产科学, 2010, 17(1)： 103-109.

[37］周九州. 湘江与洞庭湖水体氮素时空变化特征及湘江水体中氮浓度预测方法研究 [D ]. 长沙: 湖南农业大学, 2010.

[38] 韩芗, 李恒鹏, 聂小飞, 徐昔保. 太湖上游低山丘陵地区不同用地类型氮、磷收支平衡特征. 湖泊科学, 2012, 24(6) : 829-837.

[39] 朱广伟, 陈伟民, 李恒鹏, 任理, 顾创, 赵林林, 高永霞, 贺再再, 张运林. 天目湖沙河水库水质对流域开发与保护的响应. 湖泊科学, $2013,25(6): 809-817$.

[40] 石炎, 何雄波, 李军, 沈忱, 冯晨, 郭峻宏, 招春旭, 康斌. 基于稳定同位素方法的闽江口常见鱼类群落营养结构的季节性变化. 应用生 态学报, 2018, 29(10): 3457-3463.

［41］易现峰，张晓爱. 稳定性同位素技术在生态学上的应用. 生态学杂志, 2005，24(3) : 306-314.

［42］ J亚芹, 韩莹, 李兆富. 2000 年以来天目湖流域茶园分布变化及趋势模拟. 湖泊科学, 2013, 25(6) : 799-808.

[43] Peterson B J. Stable isotopes as tracers of organic matter input and transfer in benthic food webs: a review. Acta Oecologica, 1999, 20(4): 479- 487. 
[44] Lake J L, McKinney R A, Osterman F A, Pruell R J, Kiddon J, Ryba S A, Libby A D. Stable nitrogen isotopes as indicators of anthropogenic activities in small freshwater systems. Canadian Journal of Fisheries and Aquatic Sciences, 2001, 58(5): 870-878.

[45] Kendall C, Silva S R, Kelly V J. Carbon and nitrogen isotopic compositions of particulate organic matter in four large river systems across the United States. Hydrological Processes, 2001, 15(7): 1301- 1346.

[46] Kendall C, Aravena R. Nitrate isotopes in groundwater systems//Cook P G, Herczeg A L, eds. Environmental Tracers in Subsurface Hydrology. Boston: Springer, 2000: 261-297.

[47] Iglesias C, Meerhoff M, Johansson L S, González-Bergonzoni I, Mazzeo N, Pacheco J P, Mello F T D, Goyenola G, Lauridsen T L, Søndergaard M, Davidson T A, Jeppesen E. Stable isotope analysis confirms substantial differences between subtropical and temperate shallow lake food webs. Hydrobiologia, 2017, 784(1): 111-123.

[48] 李斌, 王志坚, 徐丹丹, 王永明, 陶敏. 川东南小型水库营养结构特征的稳定 C、N 同位素分析. 水生生物学报, 2017, 41(6) : 1345-1353.

附录 1 大溪水库和沙河水库不同季度内主要鱼类碳氮稳定同位素值

Appendix $1 \quad \delta^{13} \mathrm{C}$ and $\delta^{15} \mathrm{~N}$ value of main fishes during different seasons in Daxi and Shahe Reservoir

\begin{tabular}{|c|c|c|c|c|c|c|c|}
\hline \multirow{2}{*}{$\begin{array}{l}\text { 水域 } \\
\text { Waters }\end{array}$} & \multirow{2}{*}{$\begin{array}{l}\text { 物种 } \\
\text { Species }\end{array}$} & \multicolumn{2}{|c|}{ 春季 Spring } & \multicolumn{2}{|c|}{ 夏季 Summer } & \multicolumn{2}{|c|}{ 秋季 Autumn } \\
\hline & & $\delta^{13} \mathrm{C}$ & $\delta^{15} \mathrm{~N}$ & $\delta^{13} \mathrm{C}$ & $\delta^{15} \mathrm{~N}$ & $\delta^{13} \mathrm{C}$ & $\delta^{15} \mathrm{~N}$ \\
\hline 大溪水库 & 贝氏粲 & - & - & - & - & $-27.32 \pm 0.10$ & $12.87 \pm 0.59$ \\
\hline \multirow[t]{27}{*}{ Daxi Reservoir } & 粲 & $-26.24 \pm 1.42$ & $10.82 \pm 1.42$ & $-26.92 \pm 0.17$ & $12.82 \pm 0.33$ & $-27.08 \pm 0.63$ & $11.94 \pm 0.39$ \\
\hline & 达氏鲌 & $-28.16 \pm 0.19$ & $15.40 \pm 0.03$ & $-27.61 \pm 0.19$ & $13.98 \pm 0.29$ & $-26.79 \pm 0.39$ & $12.11 \pm 0.02$ \\
\hline & 大鯺鱊 & $-24.51 \pm 1.31$ & $11.90 \pm 0.60$ & $-24.92 \pm 1.25$ & $13.17 \pm 0.99$ & $-26.14 \pm 0.34$ & $10.11 \pm 0.34$ \\
\hline & 大眼鳜 & -25.34 & 14.10 & -25.42 & 14.68 & - & - \\
\hline & 䱌 & -26.37 & 15.19 & $-24.81 \pm 1.23$ & $15.52 \pm 1.14$ & -24.52 & 14.80 \\
\hline & 河川沙塘鳢 & $-25.44 \pm 0.72$ & $14.18 \pm 0.89$ & - & - & - & - \\
\hline & 黑鮱鳈 & $-25.18 \pm 1.18$ & $12.77 \pm 0.92$ & $-24.67 \pm 0.94$ & $14.70 \pm 0.76$ & $-25.09 \pm 1.56$ & $11.75 \pm 1.29$ \\
\hline & 花鱼骨 & $-28.78 \pm 0.15$ & $14.47 \pm 0.57$ & $-27.44 \pm 0.47$ & $14.97 \pm 0.20$ & -27.95 & 13.37 \\
\hline & 华鳈 & - & - & $-26.58 \pm 0.90$ & $14.56 \pm 0.85$ & $-26.11 \pm 1.34$ & $12.14 \pm 0.17$ \\
\hline & 黄颡鱼 & $-25.94 \pm 1.23$ & $12.89 \pm 0.78$ & $-29.38 \pm 0.83$ & $14.87 \pm 0.76$ & - & - \\
\hline & 黄尾鲖 & - & - & - & - & -21.82 & 8.48 \\
\hline & 鲫 & $-26.22 \pm 0.71$ & $13.70 \pm 1.08$ & $-28.12 \pm 2.21$ & $13.80 \pm 0.22$ & $-29.48 \pm 0.63$ & $11.70 \pm 0.94$ \\
\hline & 鲤 & -26.83 & 11.13 & - & - & -25.64 & 12.02 \\
\hline & 鲢 & $-28.49 \pm 0.15$ & $13.15 \pm 0.24$ & $-27.72 \pm 0.83$ & $12.74 \pm 1.52$ & -26.48 & 9.42 \\
\hline & 麦穗鱼 & $-25.82 \pm 0.94$ & $11.26 \pm 1.64$ & - & - & -27.53 & 10.04 \\
\hline & 蒙古鲌 & -28.33 & 14.63 & $-26.85 \pm 0.33$ & $14.44 \pm 0.77$ & $-27.02 \pm 0.26$ & $13.32 \pm 0.57$ \\
\hline & 蛇鮈 & $-23.91 \pm 0.62$ & $12.92 \pm 1.55$ & - & - & - & - \\
\hline & 泥鳅 & - & - & - & - & -27.72 & 11.71 \\
\hline & 翘嘴鲌 & - & - & $-28.47 \pm 0.42$ & $17.24 \pm 0.55$ & $-26.93 \pm 0.35$ & $13.82 \pm 0.41$ \\
\hline & 似刺鳊鮈 & $-27.37 \pm 0.29$ & $15.03 \pm 0.30$ & $-26.56 \pm 1.00$ & $15.31 \pm 0.72$ & $-27.16 \pm 0.87$ & $13.42 \pm 1.43$ \\
\hline & 似鱎 & $-28.39 \pm 0.26$ & $13.57 \pm 0.69$ & $-28.01 \pm 0.17$ & $13.71 \pm 0.19$ & $-28.06 \pm 0.11$ & $12.25 \pm 0.46$ \\
\hline & 兴凯鱊 & -19.95 & 9.37 & - & - & $-24.89 \pm 0.28$ & $10.66 \pm 0.83$ \\
\hline & 银鮈 & $-25.69 \pm 0.65$ & $12.36 \pm 0.55$ & $-27.01 \pm 0.35$ & $13.68 \pm 0.56$ & $-25.48 \pm 0.73$ & $13.07 \pm 0.81$ \\
\hline & 鳙 & $-24.08 \pm 1.09$ & $11.55 \pm 2.86$ & $-27.00 \pm 1.65$ & $12.89 \pm 1.10$ & $-27.12 \pm 0.12$ & $11.71 \pm 0.53$ \\
\hline & 长须黄颡鱼 & -31.75 & 13.03 & - & - & - & - \\
\hline & 中华鳑鲏 & $-24.76 \pm 0.60$ & $11.82 \pm 0.50$ & - & - & $-23.87 \pm 1.73$ & $10.99 \pm 0.66$ \\
\hline & 子陵吻虾虎鱼 & $-24.52 \pm 1.65$ & $14.36 \pm 0.25$ & -24.08 & 13.77 & - & - \\
\hline 沙河水库 & 粲 & $-28.40 \pm 2.28$ & $12.52 \pm 1.76$ & $-27.87 \pm 1.05$ & $12.81 \pm 1.18$ & $-31.13 \pm 0.16$ & $13.80 \pm 0.56$ \\
\hline \multirow[t]{5}{*}{ Shahe Reservoir } & 达氏鲌 & $-29.93 \pm 1.54$ & $14.96 \pm 1.03$ & $-29.73 \pm 0.87$ & $15.36 \pm 0.47$ & $-29.43 \pm 1.31$ & $15.33 \pm 0.32$ \\
\hline & 大鳞副泥鳅 & - & - & -23.50 & 7.92 & - & - \\
\hline & 大鯺鱊 & $-27.80 \pm 1.29$ & $13.44 \pm 0.32$ & $-26.23 \pm 1.69$ & $14.16 \pm 0.38$ & $-28.02 \pm 1.94$ & $14.20 \pm 1.18$ \\
\hline & 大眼鳜 & -26.80 & 15.22 & $-26.72 \pm 0.74$ & $15.88 \pm 0.67$ & - & - \\
\hline & 鳜 & -27.11 & 14.37 & $-27.13 \pm 0.49$ & $15.47 \pm 0.92$ & $-27.13 \pm 0.56$ & $14.81 \pm 0.04$ \\
\hline
\end{tabular}




\begin{tabular}{|c|c|c|c|c|c|c|c|}
\hline \multirow{2}{*}{$\begin{array}{l}\text { 水域 } \\
\text { Waters }\end{array}$} & \multirow{2}{*}{$\begin{array}{l}\text { 物种 } \\
\text { Species }\end{array}$} & \multicolumn{2}{|c|}{ 春季 Spring } & \multicolumn{2}{|c|}{ 夏季 Summer } & \multicolumn{2}{|c|}{ 秋季 Autumn } \\
\hline & & $\delta^{13} \mathrm{C}$ & $\delta^{15} \mathrm{~N}$ & $\delta^{13} \mathrm{C}$ & $\delta^{15} \mathrm{~N}$ & $\delta^{13} \mathrm{C}$ & $\delta^{15} \mathrm{~N}$ \\
\hline & 河川沙塘鳢 & - & - & -26.21 & 16.55 & - & - \\
\hline & 黑鳍鳈 & $-27.81 \pm 0.26$ & $13.73 \pm 1.18$ & $-26.78 \pm 0.39$ & $14.50 \pm 0.81$ & $-26.11 \pm 0.59$ & $16.02 \pm 0.97$ \\
\hline & 红鯺原鲌 & - & - & -27.24 & 16.08 & -28.73 & 14.23 \\
\hline & 花鳃 & $-29.60 \pm 0.42$ & $12.70 \pm 0.28$ & -28.69 & 15.90 & $-29.70 \pm 0.87$ & $13.40 \pm 0.51$ \\
\hline & 华鳈 & $-29.71 \pm 0.41$ & $13.37 \pm 1.27$ & $-27.38 \pm 1.29$ & $14.66 \pm 0.65$ & $-29.66 \pm 1.01$ & $12.70 \pm 0.22$ \\
\hline & 黄颡鱼 & $-29.63 \pm 1.04$ & $13.12 \pm 0.66$ & $-29.88 \pm 2.13$ & $14.88 \pm 0.43$ & $-28.30 \pm 1.54$ & $13.09 \pm 2.29$ \\
\hline & 黄尾鲖 & $-28.60 \pm 2.49$ & $10.32 \pm 1.13$ & $-24.72 \pm 0.41$ & $12.04 \pm 0.33$ & $-25.37 \pm 1.16$ & $8.56 \pm 1.25$ \\
\hline & 鲫 & $-27.30 \pm 3.54$ & $11.80 \pm 3.37$ & $-27.47 \pm 0.32$ & $13.19 \pm 0.80$ & $-23.12 \pm 0.43$ & $8.41 \pm 0.90$ \\
\hline & 鲤 & - & - & - & - & $-29.82 \pm 1.37$ & $16.08 \pm 2.59$ \\
\hline & 鲢 & $-30.53 \pm 1.55$ & $10.32 \pm 3.05$ & $-27.61 \pm 0.98$ & $11.37 \pm 0.95$ & $-28.21 \pm 0.06$ & $13.20 \pm 0.20$ \\
\hline & 麦穗鱼 & $-26.55 \pm 2.26$ & $12.52 \pm 0.53$ & - & - & -29.29 & 13.11 \\
\hline & 蒙古鲌 & $-30.47 \pm 0.84$ & $14.65 \pm 0.49$ & $-28.62 \pm 1.01$ & $14.02 \pm 0.46$ & $-30.01 \pm 0.25$ & $16.17 \pm 0.22$ \\
\hline & 泥鳅 & $-23.19 \pm 0.33$ & $6.86 \pm 1.70$ & -24.15 & 9.97 & - & - \\
\hline & 鲇 & -19.27 & 4.20 & - & - & - & - \\
\hline & 翅嘴鲌 & $-29.36 \pm 0.53$ & $15.31 \pm 1.00$ & $-25.93 \pm 0.11$ & $14.86 \pm 0.04$ & $-28.53 \pm 0.46$ & $15.99 \pm 0.39$ \\
\hline & 细鳞鲖 & $-32.09 \pm 0.31$ & $10.47 \pm 0.84$ & $-24.83 \pm 1.49$ & $10.67 \pm 0.10$ & $-29.59 \pm 2.11$ & $8.77 \pm 1.52$ \\
\hline & 蛇鮈 & - & - & -24.99 & 14.73 & - & - \\
\hline & 似鱎 & - & - & $-29.46 \pm 0.49$ & $13.72 \pm 0.68$ & $-30.86 \pm 0.41$ & $15.91 \pm 0.67$ \\
\hline & 兴凯鱊 & $-21.53 \pm 0.75$ & $10.02 \pm 0.73$ & $-19.77 \pm 1.45$ & $12.63 \pm 0.10$ & - & - \\
\hline & 银鮈 & $-28.55 \pm 0.49$ & $14.63 \pm 0.49$ & $-26.84 \pm 1.44$ & $13.85 \pm 0.49$ & $-27.15 \pm 0.60$ & $15.56 \pm 1.01$ \\
\hline & 鳙 & - & - & $-29.07 \pm 0.05$ & $15.36 \pm 1.21$ & $-29.05 \pm 0.24$ & $14.95 \pm 0.34$ \\
\hline & 中华鳑鲏 & $-25.96 \pm 0.55$ & $11.64 \pm 0.92$ & - & - & - & - \\
\hline & 子陵吻虾虎鱼 & $-26.60 \pm 3.06$ & $13.00 \pm 0.98$ & - & - & - & - \\
\hline
\end{tabular}

